\title{
Metabolic Profiling and Cold-Starvation Stress Response of Oxygen-Tolerant Lactobacillus gasseri Strains Cultured in Batch Bioreactor
}

\author{
Diamante Maresca, Francesca De Filippis ${ }^{\circledR}$, Alessandro Robertiello and Gianluigi Mauriello*(1) \\ Department of Agricultural Sciences, University of Naples Federico II, 80055 Portici, NA, Italy \\ * Correspondence: giamauri@unina.it
}

Received: 18 May 2019; Accepted: 10 July 2019; Published: 15 July 2019

\begin{abstract}
Phenotypic and genotypic evidence indicates that many LAB strains can grow in presence of oxygen and can shift from fermentative to aerobic and/or respiratory metabolism. The aerobic and respiratory growth of several LAB species have been studied, allowing the selection of strains showing improved biomass production, long-term survival, and resistance under oxygen and stress conditions. The aim of this work was to observe the adaptation of two Lactobacillus gasseri strains, described in a previous work, to aerobic (air injection) and respiratory (air injection plus hemin and menaquionone) conditions obtained in a batch bioreactor. One strain showed the higher biomass production and oxygen consumption as well as the lower acidification in respiratory condition. Instead, the other one grew better in aerobic condition, even though the higher resistance to cold-starvation stress was registered in respiratory condition. In silico analysis revealed notable differences between AL3 and AL5 genomes and that of the type strain. This work contributes to understanding the adaptation response of lactobacilli to aerobic and respiratory metabolism. We demonstrated that the supposed activation of respiratory metabolism may provide several modifications to cell physiology. These features may be relevant in some technological and health-promoting applications, including starter and probiotic formulations.
\end{abstract}

Keywords: aerobic and respiratory metabolism; lactic acid bacteria; cold-starvation stress; tricarboxylic acid cycle; in silico analysis

\section{Introduction}

The fermentative metabolism of lactic acid bacteria (LAB) has been intensively studied because of its technological implications in the food industry. In recent years, phenotypic and genotypic evidence has indicated that many LAB strains can grow in the presence of oxygen and can shift from fermentative to aerobic and/or respiratory metabolism [1]. In particular, some LAB strains can consume oxygen through the action of flavoprotein oxidases (e.g., NADH oxidase, NOX; pyruvate oxidase, POX; lactate oxidase, LOX; $\alpha$-glycerophosphate oxidase) and can activate aerobic metabolism by the pyruvate oxidase-acetate/kinase (POX-ACK) pathway [2]. Moreover, several LAB strains can perform respiratory metabolism in the presence of oxygen by activating a minimal electron transport chain when exogenous heme and/or menaquinone are provided [3].

Aerobic and respiratory metabolism have been widely investigated in some strains of Lactobacillus reuteri and Lactobacillus spicheri [4], in the Lactobacillus casei group [5,6], and in the Lactobacillus plantarum group [7-10]. Moreover, some of these studies led to the selection of strains that improved the features of foods when used like adjunct cultures [11,12]. Advances in this area have led to an increased interest in the physiology, metabolism, and genetics of LAB's aerobic lifestyle. However, very limited data are currently available on Lactobacillus johnsonii and Lactobacillus gasseri, although several strains have been 
extensively studied for their technological and probiotic properties [13,14]. Lb. johnsonii and Lb. gasseri belong to the Lactobacillus acidophilus group that was recently merged with the Lactobacillus delbrueckii group [15]. Currently, only the probiotic Lb. johnsonii NCC 533 has been studied to help provide a more global understanding of the molecular responses to the presence of oxygen [16,17].

Although genetic studies have helped explain the consequences of $\mathrm{O}_{2}$ and $\mathrm{CO}_{2}$ exposure on the physiology of $L b$. johnsonii NCC 533, they have not fully addressed the complexity of the mechanisms of aerobic metabolism and the oxidative stress response. In our previous microplate screening study, the adaptation response to aerobic and respiratory cultivation was investigated in $34 \mathrm{Lb}$. johnsonii/gasseri strains isolated from the stools of breast fed babies [18]. The strains AL3 and AL5 were selected for their ability to grow under aerobic and/or respiratory conditions, as well as to scavenge hydrogen peroxide $\left(\mathrm{H}_{2} \mathrm{O}_{2}\right)$ and/or reactive oxygen species (ROS) [18]. The whole-genome sequencing of both strains revealed that AL3 and AL5 belong to the Lb. gasseri species and that they possess genes involved in aerobic and respiratory metabolism and oxidative stress resistance [19].

The present work aimed to collect biochemical evidence (i.e., sugar consumption and metabolite production) of the activation of the aerobic and/or respiratory pathway in the strain Lb. gasseri AL3 and AL5 during their cultivation in a batch bioreactor. Furthermore, resistance to the cold-starvation stress of aerobic and respiratory cultures was assessed. Finally, a comparative in silico analysis was carried out to reveal differences in genome composition among AL3, AL5 and the type strain Lb. gasseri DSM $20243^{\mathrm{T}}$.

\section{Materials and Methods}

\subsection{Bacterial Strains}

Lactobacillus gasseri AL3 and AL5 and Lb. gasseri DSM 20243 ${ }^{\mathrm{T}}$ were routinely propagated in aerobic condition at $37^{\circ} \mathrm{C}$ for $24 \mathrm{~h}$ in Weissella Medium Broth $\mathrm{pH}$ 6.8 [9] modified by adding $10 \mathrm{~g} / \mathrm{L}$ of fructose (mWMB).

\subsection{Batch bioreactor cultivation}

Strains were grown in $\mathrm{mWMB}$ at $37^{\circ} \mathrm{C}$ for $30 \mathrm{~h}$ using a $1 \mathrm{~L}$ fermentation bioreactor (Applikon Biotechnology, Schiedam, Netherlands) under the following growth conditions: i) nitrogen $(0.45 \mu \mathrm{m}$ filter sterilised) flow at $0.1 \mathrm{vol} / \mathrm{vol} / \mathrm{min}$, stirrer speed $150 \mathrm{rpm}$ (anaerobiosis, AN); ii) air $(0.45 \mu \mathrm{m}$ filter sterilised) flow at $0.1 \mathrm{vol} / \mathrm{vol} / \mathrm{min}$, stirrer speed $150 \mathrm{rpm}$ (aerobiosis, AE); iii), AE condition supplemented with $2.5 \mu \mathrm{g} / \mathrm{mL}$ of hemin and $1 \mu \mathrm{g} / \mathrm{mL}$ of menaquinone (respiration, RS). The bioreactor was inoculated $(2 \% \mathrm{vol} / \mathrm{vol})$ with standardized $\left(\mathrm{OD}_{650}=1.0\right)$ overnight pre-cultures obtained in static and normal atmospheric condition. Dissolved oxygen concentration (DO\%) was measured using a polarographic electrode (Applikon Biotechnology, JG Delft, Netherland). Fermentation parameters such as $\mathrm{DO} \%, \mathrm{pH}$, and temperature were monitored using the ezControl system (Applikon Biotechnology, JG Delft, Netherland). Foam formation was controlled by adding $0.5 \mathrm{~mL} / \mathrm{L}$ of Antifoam 204 solution (Sigma-Aldrich, Saint Louis, MO, USA) at the medium composition. Three independent fermentation rounds were carried out for each experiment.

\subsection{Bacterial Growth Monitoring}

Bacterial growth was monitored by measuring the optical density of culture samples at $650 \mathrm{~nm}$ $\left(\mathrm{OD}_{650}\right)$ using a spectrophotometer (Eppendorf BioSpectrometer, Milan, Italy). Samples were collected immediately after inoculation and then after $3,4,5,6,7,8,9,20,22,24,26,28$, and $30 \mathrm{~h}$.

\subsection{HPLC Analysis}

Sugar consumption (glucose and fructose) and metabolite production (acetic, citric and lactic acid) were measured by HPLC analysis. Aliquots of $1 \mathrm{~mL}$ of AN, AE, and RS cultures was collected immediately after inoculation and then after $7,9,20,22,24$, and $30 \mathrm{~h}$ of cultivation and centrifuged 
at $13,000 \mathrm{~g}$ for $5 \mathrm{~min}$. The resulting supernatant was diluted in the mobile phase $\left(\mathrm{H}_{2} \mathrm{SO}_{4} 0.01 \mathrm{~N}\right) 1: 5$ (vol/vol) and filtered by AcroDisc ( $0.2 \mu \mathrm{m}$; Millipore, Burlington, MA, USA). Sugars and metabolites were quantified by a Gilson 307 Series HPLC system fitted with a MetaCarb $67 \mathrm{H} 6.5 \times 300 \mathrm{~mm}$ column (Agilent Technologies, Santa Clara, CA, USA) in an oven at $65^{\circ} \mathrm{C}$. The column was eluted at $0.4 \mathrm{~mL} / \mathrm{min}$ by a 1:9 (vol/vol) solution of $\mathrm{H}_{2} \mathrm{SO}_{4}$ in ultrapure water. A refractometer (RID 133, Gilson, Middleton, WI, USA) was used as a detector. Standards (47829 glucose, F2793 fructose, 46937 lactic acid, 71251 acetic acid and 46933 citric acid analytical standard, Sigma-Aldrich, St. Louis, MO, USA) were used for the quantification of different sugars in the samples.

\subsection{Tolerance to Cold-Starvation Stress}

Culture samples were collected at the early stationary phase, matching to $20 \mathrm{~h}$ in AE and $28 \mathrm{~h}$ in RS for AL3 and AL5, respectively, and $22 \mathrm{~h}$ in AN and AE conditions for Lb. gasseri 20243 ${ }^{\mathrm{T}}$. Samples were centrifuged at $6500 \mathrm{~g}$ for $10 \mathrm{~min}$, washed twice in $20 \mathrm{mM}$ potassium phosphate buffer $\mathrm{pH} 7.0$ (PB7), and re-suspended in PB7 to obtain a final $\mathrm{OD}_{650}=1$. Tolerance to starvation was evaluated by storing cell suspensions at $4{ }^{\circ} \mathrm{C}$ and performing a viable count on MRS Agar (Oxoid) $\left(37^{\circ} \mathrm{C}\right.$ in aerobiosis) at $0,7,14,21$, and 28 days of storage.

\subsection{Comparative in Silico Analysis}

In silico analysis was carried out in order to compare the presence of 33 genes (29 genes and cyd operon) coding for the main enzymes involved in aerobic (pyruvate oxidase (POX), lactate oxidase (LOX), L-aminoacid oxidase (LAO), NADH oxidase (NOX) and acetate kinase (ACK)), respiratory metabolism (NADH dehydrogenase $(\mathrm{NDH})$, ubiquinone/menaquinone biosynthesis C-methylase (UbiE), cytochrome bd-I oxidase (CydABCD)) and oxidative stress response (NADH-peroxidase (NPR), glutathione reductase (GOR), glutathione peroxidase (GOP), $\gamma$-glutamylcystiene synthetase (GshA), glutathione synthetase (GshB), bifunctional glutamate-cysteine ligase/glutathione synthetase (GshF), thioredoxin reductase $(\operatorname{Tr} x \mathrm{R})$, thioredoxin peroxidase $(\operatorname{Tr} x \mathrm{P})$, superoxide dismutase (SOD), catalase (CAT), manganese catalase (Mn-CAT), catalase-peroxidase (CATG), and DNA binding protein from starved cells (Dps)) in finished genome of Lb. gasseri DSM $20243^{\mathrm{T}}$ (NCBI database; http://www.ncbi.nlm. nih.gov) and in draft genome sequences of Lb. gasseri AL3 and AL5 (DDBJ/ENA/GenBank, accession numbers MTZT00000000 and MUJA00000000, respectively). Furthermore, predicted genes of Lb. gasseri AL3 and AL5 [19] were queried in the NCBI database against the main enzymes involved in the partial tricarboxylic acid (TCA) cycle of LAB, including gamma (CitD), beta (CitE), and alpha (CitF) subunits of citrate lyase (CL), citrate permease (CitP), oxaloacetate decarboxylase (AOD), pyruvate carboxylase (PYC), malate dehydrogenase (MDH), fumarate hydratase (FH), and succinate dehydrogenase (SDH). The same enzymes were also found in Lb. gasseri DSM $20243^{\mathrm{T}}$ genome. All genes are reported in

\subsection{Data Analysis}

Analyses were carried out in triplicate and all values were expressed as mean and standard deviation. Two-way Anova tests and t-test analyses (Microsoft Excel for Mac version 11.5) were performed to evaluate significant differences $(p<0.05)$ between means.

\section{Results}

\subsection{Growth Parameters and Metabolite Production}

The kinetics of growth, $\mathrm{DO} \%$, and $\mathrm{pH}$ values during $\mathrm{AE}$ and $\mathrm{RS}$ growth are shown in Figure 1 for strain AL3 and in Figure 2 for strain AL5. Data for AN condition are not reported because neither strain showed the ability to grow when no air or oxygen was injected into the bioreactor.Table 1 . 
Table 1. Results of in silico analysis of genes (presence [+]/absence [-]) involved in aerobic and respiratory metabolism, stress response and in the partial tricarboxylic acid (TCA) cycle in Lb. gasseri AL3, AL5 and DSM $20243^{\mathrm{T}}$ genomes from NCBI database (http://www.ncbi.nlm.nih.gov).

\begin{tabular}{|c|c|c|c|c|}
\hline \multirow{2}{*}{ Group } & \multirow{2}{*}{ Genes } & \multicolumn{3}{|c|}{ Strains } \\
\hline & & AL3 & AL5 & DSM $20243^{T}$ \\
\hline \multirow{5}{*}{$\begin{array}{l}\text { Aerobic } \\
\text { metabolism }\end{array}$} & pox (pyruvate oxidase) & + & + & + \\
\hline & ack (acetate kinase) & + & + & + \\
\hline & lox (lactate oxidase) & + & + & - \\
\hline & nox (NADH oxidase) & + & + & - \\
\hline & lao (L-amino acid oxidase) & + & - & - \\
\hline \multirow{3}{*}{$\begin{array}{l}\text { Respiratory } \\
\text { metabolism }\end{array}$} & $n d h$ (NADH dehydrogenase) & + & + & + \\
\hline & $\begin{array}{l}\text { ubiE (ubiquinone/menaquinone } \\
\text { biosynthesis methyltrasferase) }\end{array}$ & + & + & + \\
\hline & $\begin{array}{l}c y d A B C D \text { (cytochrome bd-I oxidase } \\
\text { operon) }\end{array}$ & + & + & + \\
\hline \multirow{13}{*}{ Stress response } & $n p r$ (NADH peroxidase) & + & + & + \\
\hline & gor (glutathione reductase) & + & + & + \\
\hline & gop (glutathione peroxidase) & - & - & - \\
\hline & GshA ( $\gamma$-glutamylcystiene synthetase) & + & + & - \\
\hline & GshB (glutathione synthetase) & - & - & - \\
\hline & $\begin{array}{l}\text { GshF (bifunctional glutamate-cysteine } \\
\text { ligase/glutathione synthetase) }\end{array}$ & - & - & - \\
\hline & $\operatorname{Tr} x R$ (thioredoxin reductase) & + & + & + \\
\hline & $\operatorname{Tr} x P$ (thioredoxin peroxidase) & + & + & + \\
\hline & SOD (superoxide dismutase) & + & + & - \\
\hline & Kat (catalase) & - & - & - \\
\hline & MnKat (Manganese-catalase) & - & - & - \\
\hline & KatG (catalase-peroxidase) & - & - & - \\
\hline & $\begin{array}{l}D p s \text { (DNA binding protein from } \\
\text { starved cells) }\end{array}$ & + & + & + \\
\hline \multirow{9}{*}{$\begin{array}{l}\text { Partial tricarboxylic } \\
\text { acid (TCA) cycle }\end{array}$} & CitD (gamma subunits of citrate lyase) & + & + & - \\
\hline & CitE (beta subunits of citrate lyase) & + & + & - \\
\hline & CitF (alpha subunits of citrate lyase) & + & + & - \\
\hline & CitP (citrate permease) & + & + & - \\
\hline & $A O D$ (oxaloacetate decarboxylase) & - & - & - \\
\hline & PYC (pyruvate carboxylase) & - & - & - \\
\hline & $M D H$ (malate dehydrogenase) & + & + & + \\
\hline & FH (fumarate hydratase) & + & + & + \\
\hline & SDH (succinate dehydrogenase) & + & + & - \\
\hline
\end{tabular}

The growth of AL3 was impaired in AE condition compared to in RS condition. In addition, AL3 achieved its highest cell density $\left(\mathrm{OD}_{650}=0.8 \pm 0.1\right)$ at $20 \mathrm{~h}$ of growth in AE conditions (Figure $\left.1 \mathrm{~A}\right)$, while in RS condition, AL3 continued to grow up to $28 \mathrm{~h}$, ultimately showing a greater cell density $\left(\mathrm{OD}_{650}=1.65 \pm 0.06\right)$ (Figure 1B). Of note, the growth curve of AL3 showed a diauxic-like trend in RS condition (Figure 1, panel B). A comparison of the kinetics of DO\% showed that AL3 consumed oxygen up to $20 \mathrm{~h}$ of growth in AE condition (Figure 1A), but up to $28 \mathrm{~h}$ in RS condition (Figure 1B). A pH decrease was observed until the strain entered stationary phase $(20 \mathrm{~h})$ during AE growth (Figure 1C), while a very low $\mathrm{pH}$ decrease was observed from $20 \mathrm{~h}$ onwards in RS condition, despite the increase of cell density until $28 \mathrm{~h}$ (Figure 1D). Strain AL5 grew better in AE (Figure 2A) than in RS condition (Figure $2 \mathrm{~B})$. The growth of this strain in $\mathrm{AE}$ condition was associated with a significant $(p<0.05)$ decrease of both $\mathrm{DO} \%$ (Figure $2 \mathrm{~A}$ ) and $\mathrm{pH}$ (Figure $2 \mathrm{C}$ ), until the strain entered stationary phase $(20 \mathrm{~h})$. On the contrary, growth in RS condition continued from $20 \mathrm{~h}$ onwards without oxygen consumption (Figure 2B), but a simultaneous decrease in $\mathrm{pH}$ was observed (Figure 2D). Similar to AL3, the growth curve of AL5 showed a diauxic-like trend in RS condition (Figure 2B). As expected, the reference strain 
Lb. gasseri $20243^{\mathrm{T}}$ grew better in AN (Figure 3A) than in AE condition (Figure 3B) and was not able to grow in RS condition.
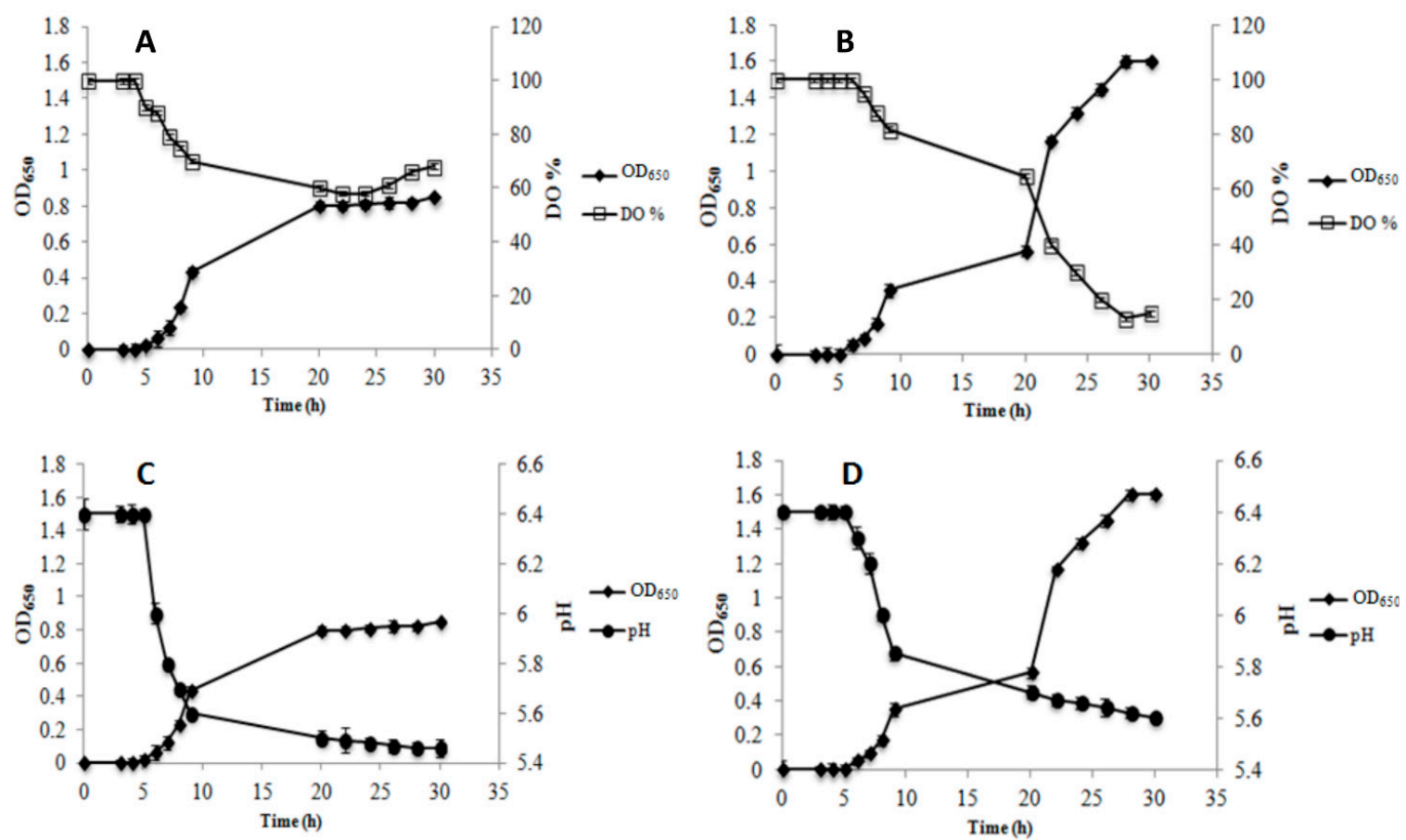

Figure 1. Growth kinetic $\left(\mathrm{OD}_{650}\right)$, dissolved oxygen concentration $(\mathrm{DO} \%)$ and $\mathrm{pH}$ during aerobic $(\mathrm{AE}$, panel $\mathbf{A}$ and $\mathbf{C}$ ) and respiratory (RS, panel $\mathbf{B}$ and $\mathbf{D}$ ) cultivation of Lb. gasseri AL3 in a batch bioreactor.
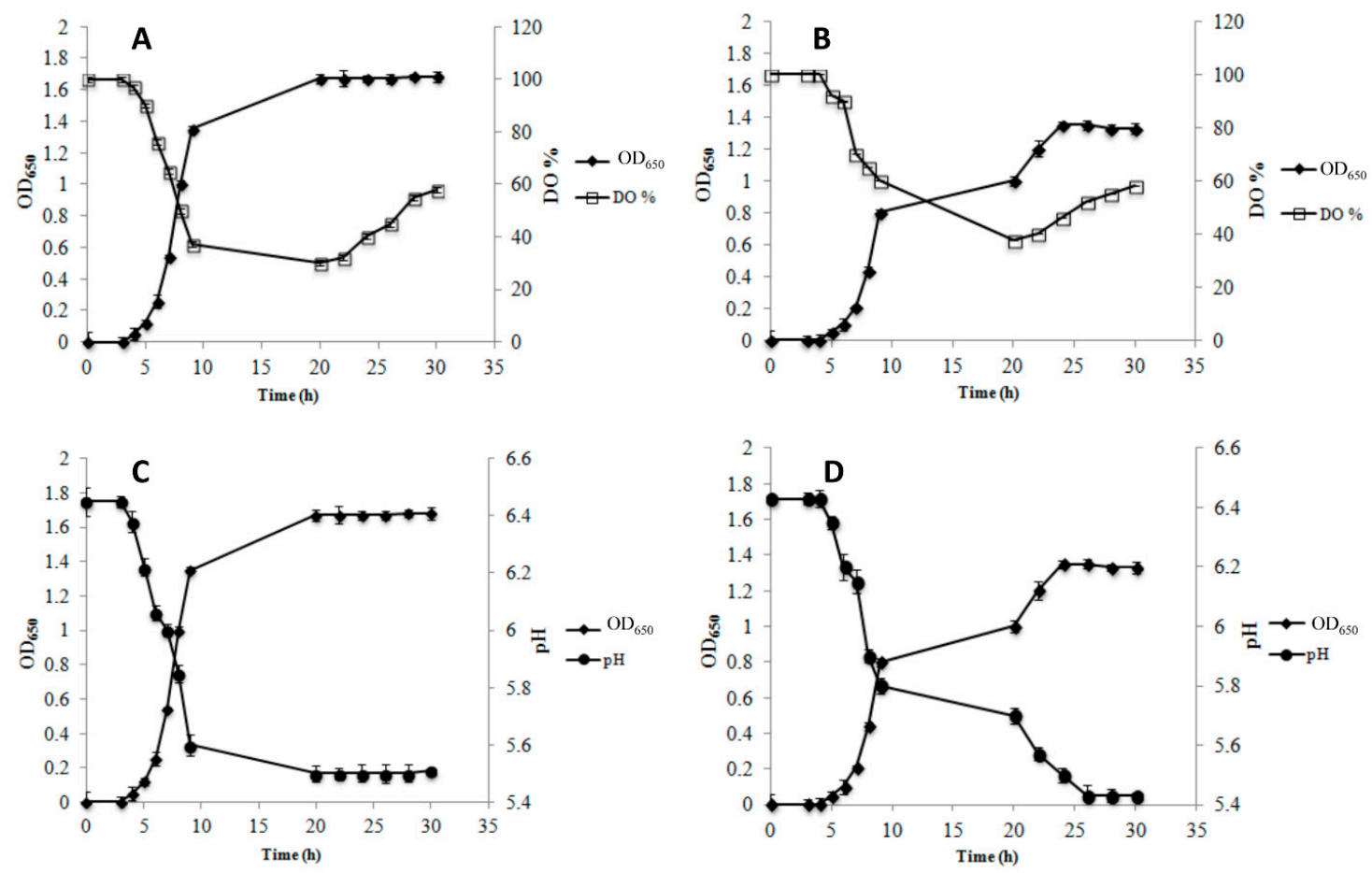

Figure 2. Growth kinetic $\left(\mathrm{OD}_{650}\right)$, dissolved oxygen concentration $(\mathrm{DO} \%)$ and $\mathrm{pH}$ during aerobic $(\mathrm{AE}$, panel A and C) and respiratory (RS, panel B and D) cultivation of Lb. gasseri AL5 in a batch bioreactor. 


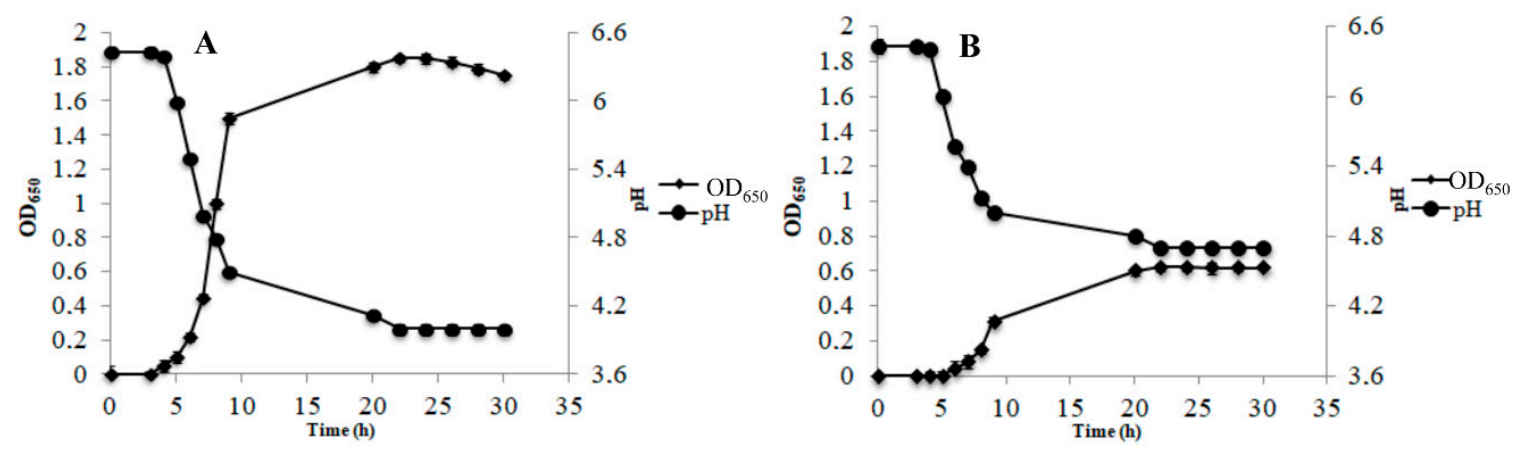

Figure 3. Growth kinetic $\left(\mathrm{OD}_{650}\right)$ and $\mathrm{pH}$ during anaerobic $(\mathrm{AN}$, panel $\mathrm{A})$ and aerobic (AE, panel B) cultivation of $L b$. gasseri $20243^{\mathrm{T}}$ in a batch bioreactor.

Lb. gasseri $20243^{\mathrm{T}}$ achieved the highest cell density $\left(\mathrm{OD}_{650}=1.8 \pm 0.09\right)$ after $22 \mathrm{~h}$ and dramatically reduced the $\mathrm{pH}$ of the medium. AE condition heavily impaired the growth of Lb. gasseri $20243^{\mathrm{T}}$ (Figure 3B) and the strain was not able to consume oxygen.

Results of the substrate consumption and metabolite production tests during growth in $\mathrm{AE}$ and RS conditions are shown in Figure 4 for AL3 and Figure 5 for AL5.
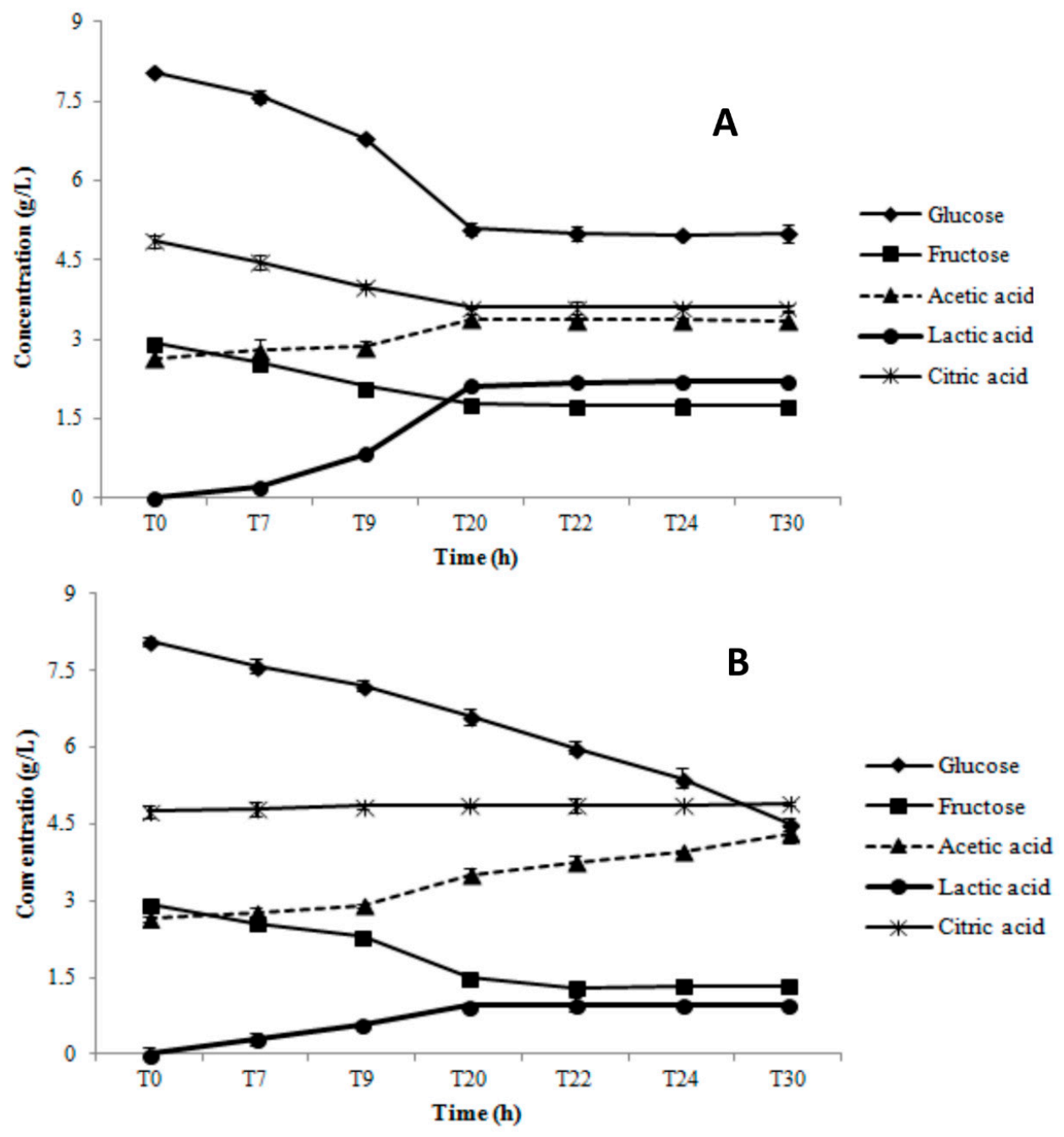

Figure 4. Substrate consumption and metabolites production during aerobic (AE, panel A) and respiratory (RS, panel B) cultivation of $L b$. gasseri AL3 in a batch bioreactor. 

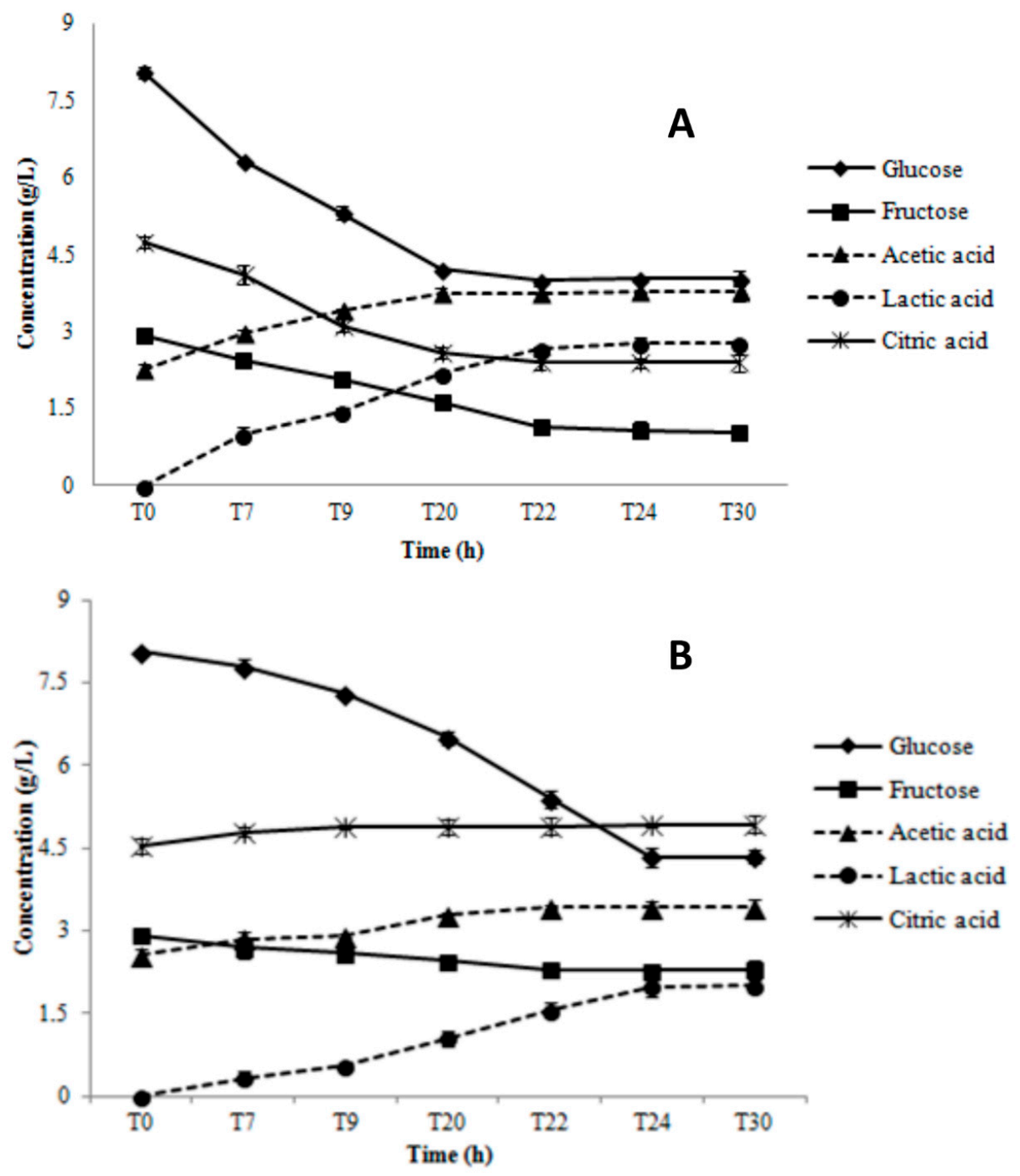

Figure 5. Substrate consumption and metabolites production during aerobic (AE, panel A) and respiratory (RS, panel B) cultivation of $L b$. gasseri AL5 in a batch bioreactor.

AL3 consumed glucose $(2.8 \pm 0.1 \mathrm{~g} / \mathrm{L})$, fructose $(1.0 \pm 0.08 \mathrm{~g} / \mathrm{L})$, and citric acid $(0.7 \pm 0.09 \mathrm{~g} / \mathrm{L})$ only throughout the first $20 \mathrm{~h}$ of growth in AE (Figure 4A). Lactic acid was the main end-product $(2.45 \pm 0.1$ $\mathrm{g} / \mathrm{L})$, but a small quantity of acetic acid $(0.35 \pm 0.1 \mathrm{~g} / \mathrm{L})$ was also produced (Figure $4 \mathrm{~A})$. In RS condition, there was constant glucose consumption during the whole monitoring period $(3.6 \pm 0.1 \mathrm{~g} / \mathrm{L})$, which was remarkably higher than in $\mathrm{AE}$ condition (Figure 4B). However, the trend and quantity of fructose depletion $(1.1 \pm 0.09 \mathrm{~g} / \mathrm{L})$ in RS was similar to that in AE condition (Figure 4B). The highest lactic acid concentration $(1.02 \pm 0.06 \mathrm{~g} / \mathrm{L})$ was obtained at $20 \mathrm{~h}$, significantly lower than that registered in $\mathrm{AE}$ condition $(2.45 \pm 0.1 \mathrm{~g} / \mathrm{L})$. However, we also observed an acetic acid production level of up to $1.9 \pm$ $0.05 \mathrm{~g} / \mathrm{L}$ at $30 \mathrm{~h}$. AL5 consumed glucose $(3.7 \pm 0.08 \mathrm{~g} / \mathrm{L})$, fructose $(1.56 \pm 0.1 \mathrm{~g} / \mathrm{L})$, and citric acid $(1.6 \pm$ $0.07 \mathrm{~g} / \mathrm{L}$ ) until $22 \mathrm{~h}$ of growth in AE condition (Figure $5 \mathrm{~A}$ ). Moreover, a significant amount of acetic (1.5 $\pm 0.08 \mathrm{~g} / \mathrm{L})$ and lactic acid $(2.6 \pm 0.04 \mathrm{~g} / \mathrm{L})$ was produced (Figure $5 \mathrm{~A})$. The same glucose consumption $(3.75 \pm 0.1 \mathrm{~g} / \mathrm{L})$ but a lower acetic $(0.65 \pm 0.05 \mathrm{~g} / \mathrm{L})$ and lactic $(2.1 \pm 0.06 \mathrm{~g} / \mathrm{L})$ acid production were observed in RS condition (Figure $5 \mathrm{~B})$. No significant $(p>0.05)$ consumption of fructose and citric acid was registered. As shown in Figure 6, Lb. gasseri $20243^{\mathrm{T}}$ was able to consume only glucose and to produce only lactic acid in both AN (Figure 6A) and AE condition (Figure 6B). In AN condition, Lb. gasseri $20243^{\mathrm{T}}$ consumed glucose $(6.3 \pm 0.08 \mathrm{~g} / \mathrm{L})$ until $22 \mathrm{~h}$ and produced lactic acid as the main end-product $(7.1 \pm 0.09 \mathrm{~g} / \mathrm{L}$ ) (Figure 6A). In AE condition (Figure 6B), the highest glucose depletion 
$(3.40 \pm 0.06 \mathrm{~g} / \mathrm{L})$ was registered at $20 \mathrm{~h}$ and the acetic acid production $(3.05 \pm 0.07 \mathrm{~g} / \mathrm{L})$ was significantly lower than that registered in AN condition.
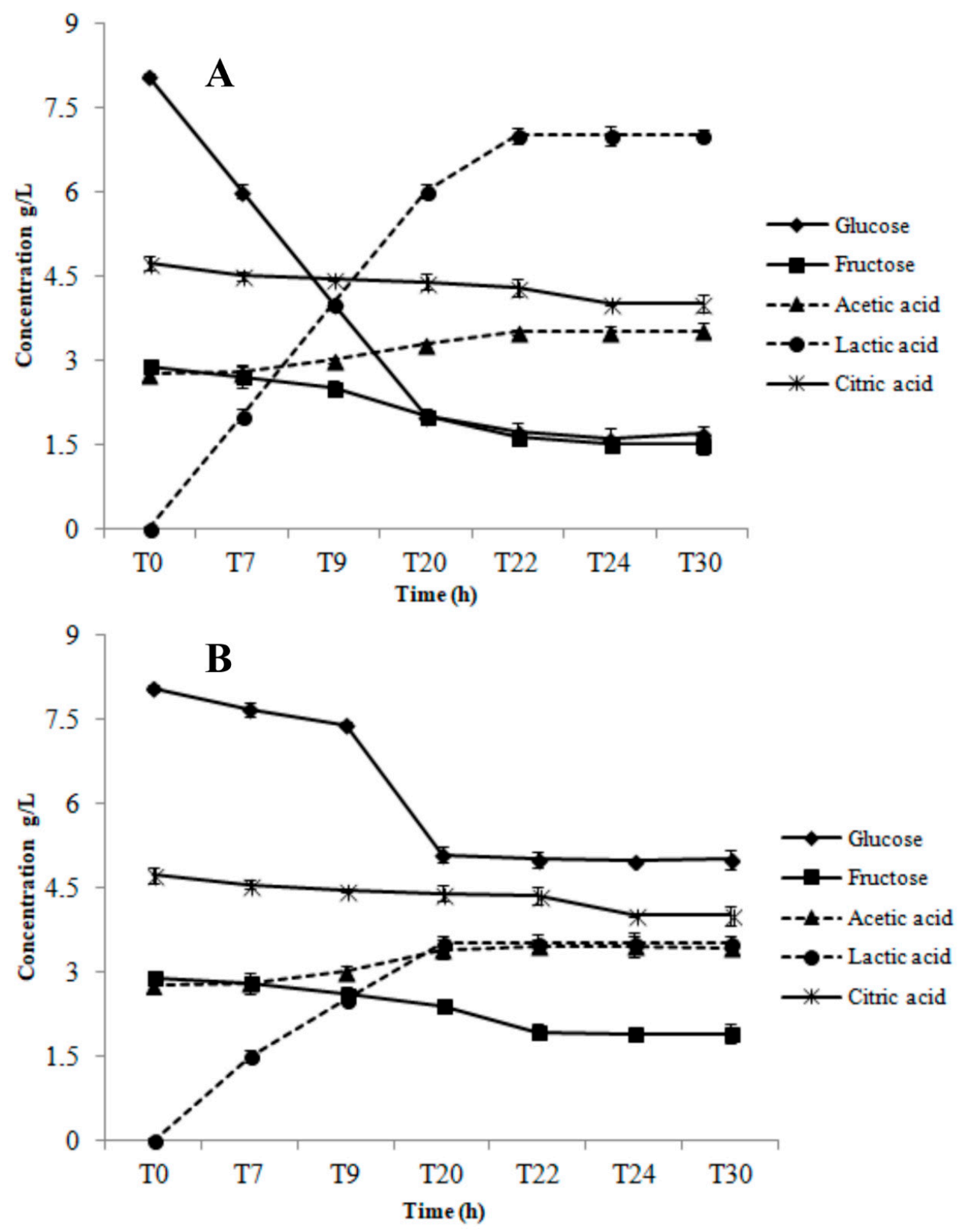

Figure 6. Substrates consumption and metabolites production during anaerobic (AN, panel A) and aerobic (AE, panel B) cultivation of $L b$. gasseri $20243^{\mathrm{T}}$ in a batch bioreactor.

\subsection{Survival of the Cells Under Cold-Starvation Stress}

Results of viable counts after 28 days of starvation at $4{ }^{\circ} \mathrm{C}$ are shown in Figure 7A.

Only the cells of AL3 from RS condition exhibited tolerance under cold-starvation stress. Indeed, no significant $(p>0.05)$ difference in cell load between starting population and that after 28 days under stress was registered. However, the AE cultivation strongly impaired the viability of both strains. In particular, at the end of the storage, a significant $(p<0.05)$ reduction of $3.08 \mathrm{Log}$ and $2.0 \mathrm{Log}$ cycles was observed for aerobic AL3 and AL5 cultures, respectively. As shown in Figure 7B, the Lb. gasseri 20243 anaerobic culture exhibited the highest tolerance to cold-starvation stress. 

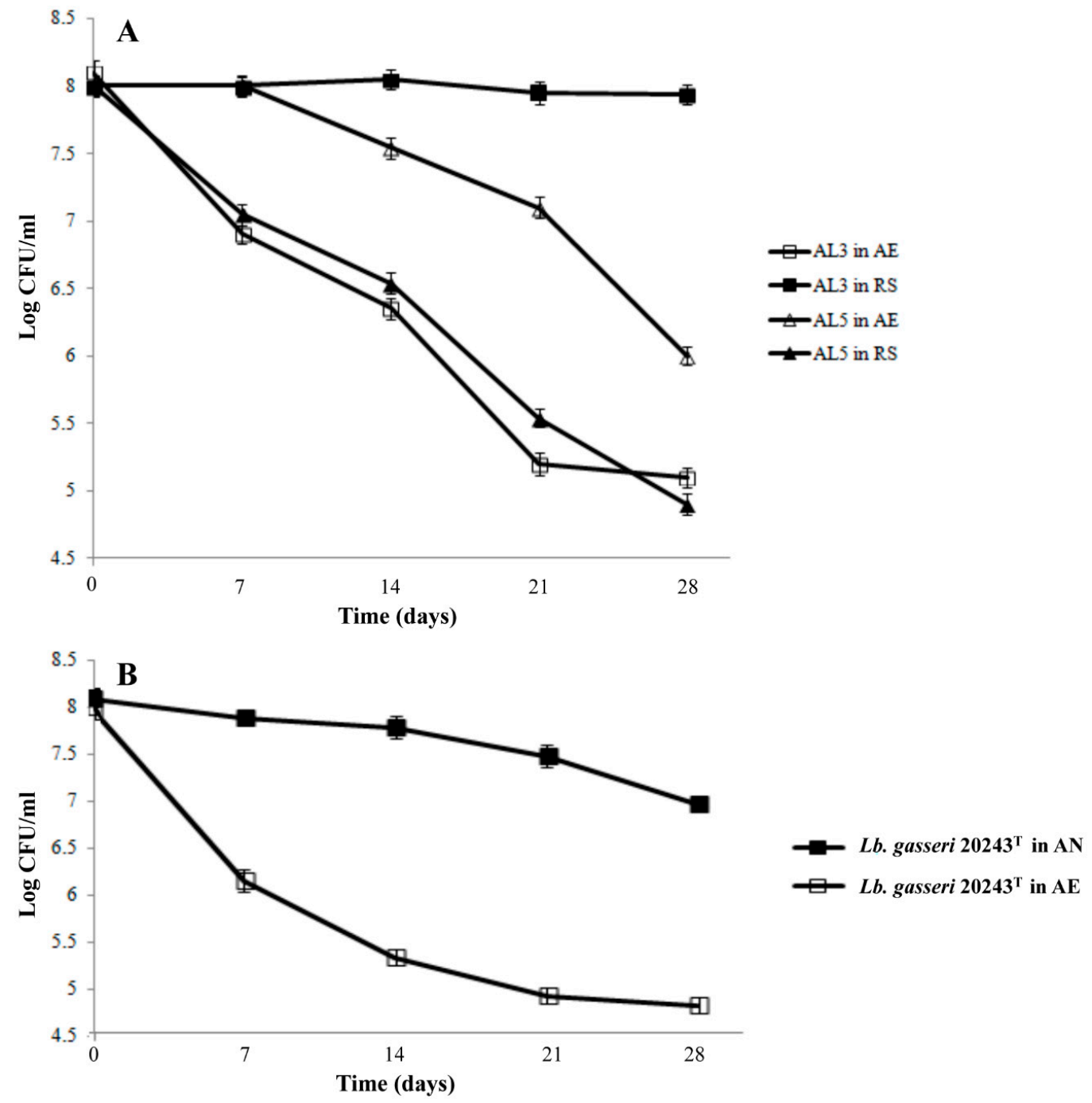

Figure 7. Viable counts (Log CFU/mL) of Lb. gasseri AL3 and AL5 strains cultivated under aerobic (AE) and respiration (RS) conditions (A) and viable counts (Log CFU/mL) of Lb. gasseri DSM 20243 ${ }^{\mathrm{T}}$ cultivated under anaerobic (AN) and aerobic (AE) conditions (B) along 28 days of starvation at $4{ }^{\circ} \mathrm{C}$.

\subsection{Comparative in Silico Analysis}

Results of the comparative in silico analysis conducted on 33 genes are summarized in Table 1. The strains AL3 and AL5 show the same profile, apart the gene encoding for the flavoprotein L-amino acid oxidase (lao, in the group of aerobic metabolism genes) that is present only in the AL3 genome. All the genes involved in the aerobic pathway that we analysed are present in AL3 and AL5 genome, wih exclusion of L-amino acid oxidase in AL5. Instead, genome of Lb. gasseri $20243^{\mathrm{T}}$ is lacking of the lox (lactate oxidase) and nox (NADH oxidase) genes. All the genes of respirartory metabolism investigated in this study ( $n d h, u b i E$ and $c y d A B C D$ ) are present in all the three strains. Of the 13 stress response genes taken into account in this work, only 7 were present in the genome of both strains AL3 and AL5, which interestingly have the gene for the synthesis of superoxide dismutase (SOD). On the other hand, Lb. gasseri $20243^{\mathrm{T}}$ is lacking GshA ( $\gamma$-glutamylcystiene synthetase) and SOD (superoxide dismutase) compared to AL3 and AL5. Remarkably, we found in the genome of AL3 and AL5 most the genes encoding for the enzymes involved in the citrate metabolism. Results of comparative analysis showed that the type strain Lb. gasseri $20243^{\mathrm{T}}$ is lacking CitD, CitE, CitF, CitP, MDH and FH genes. 


\section{Discussion}

In this work, for the first time, the ability of Lactobacillus gasseri strains to shift towards aerobic and/or respiratory metabolism was investigated during growth in a bioreactor and the effect of different conditions (AE, RS, AN) on growth performance and starvation stress tolerance was evaluated. Moreover, the metabolic profiles of AL3 and AL5 strains were investigated to provide additional biochemical evidence of the possible activation of aerobic and/or respiratory pathway. The type strain Lb. gasseri DSM $20243^{\mathrm{T}}$ was included in this study for a comparative purpose. Our results showed that Lb. gasseri AL3 grew better in RS while AL5 grew better in AE. Surprisingly, both strains didn't show any growth in AN. On the other hand, the strain $L b$. gasseri $20243^{\mathrm{T}}$ grew better in AN condition, and the presence of oxygen and respiratory cofactors (heme and menaquinone) negatively affected its growth performance. The inability of AL3 and AL5 to growth in AN could be imputable to an inadequate ATP generation. According to Hertzberger et al. [16] the growth of some Lactobacillus could be inhibited by the absence of $\mathrm{C} 1$ and $\mathrm{C} 2$ compounds like $\mathrm{CO}_{2}$ and acetate, respectively. They are produced by POX and ACK from pyruvate only in presence of oxygen. When we inject nitrogen into the substrate a gas stripping could occur, with a consequent $\mathrm{CO}_{2}$ depletion. However, this cannot explain the different behaviour in AN condition between AL3 and AL5 and Lb. gasseri $20243^{\mathrm{T}}$. Even though $L b$. gasseri is a microorganism described as an inhabitant of intestine, despite the predominantly anaerobic environment of gut, close to the mucosal tissues an oxygen gradient may be encountered [16]. Difference in growth kinetics and metabolic profiles of the three strains clearly suggests that several metabolic changes underlie the physiological characteristics observed. Moreover, results of comparative in silico analysis revealed differences in the genomic profile of $L b$. gasseri $20243^{\mathrm{T}}$ compared to that of AL3 and AL5 strain. In RS cultivation, AL3 showed increased biomass production, reduced acidification, and higher oxygen consumption. These results suggest the activation of a respiratory metabolism. Comparing the kinetics of growth, substrate consumption, and metabolite production, we hypothesize a double metabolism for this strain: it may first grow via fermentation and then via respiration. In the first $20 \mathrm{~h}$, glucose is metabolized to produce mainly lactic acid, and this could reasonably explain the observed $\mathrm{pH}$ decline. After this time, the glucose consumption continued but only acetic acid was produced. In fact, a very low decrease in $\mathrm{pH}$ was observed, despite AL3 continuing to grow and to consume oxygen. Similar results were found for a strain of Lactococcus lactis subsp. lactis by Duwat et al. [20]. These authors found that during the respiratory cultivation, obtained in presence of oxygen, hemin and menaquinone, microorganism shifted towards a respiratory metabolism. In particular, glucose consumption and lactic acid accumulation was registered in the first $7 \mathrm{~h}$ of growth, then glucose consumption continued but a reduction in lactic acid accumulation was observed, accompanied by an increase of acetate concentration. The hypothesis of a double metabolism could also explain the diauxic-like growth pattern observed. The activation of the electron transport chain could explain the high oxygen consumption (by cytochrome oxidase action) and the increased cell density (because of extra ATP generation) observed after $20 \mathrm{~h}$ of growth. Moreover, the production of acetate instead of lactate is one of the typical metabolic changes associated with respiratory growth [20-22]. AL3 possesses the main genes involved in respiratory metabolism, including NADH dehydrogenase, the cytochrome oxidase operon, and ubiquinone/menaquinone biosynthesis methyltransferase [19]. The ability of AL3 to shift toward a respiratory metabolism has also probably contributed to a remarkable improvement in cell survival under starvation stress. The analysis of the AL3 genome sequence [19] revealed a large pattern of genes involved in oxidative stress resistance mechanisms, including superoxide dismutase, NADH peroxidase, complete thioredoxin-thioredoxin reductase system, as well as member of the DNA binding proteins from starved cells which are able to provide cell protection during exposure to environmental stress, including nutritional deprivation. The robustness to starvation stress in long term survival was also previously demonstrated in respiration-competent strains of Lb. plantarum [10], Lb. casei [4], and Lactococcus lactis [23,24].

Strain AL5 showed the best growth performance in AE condition. According to the results of the AL5 draft genome analysis [19], AL5 possesses genes predicted to encode for both POX and 
acetate kinase (ACK), the main enzymes involved in the aerobic pathway. Therefore, the POX-ACK pathway activation in the presence of oxygen could explain the production of acetate and the increased biomass production, the former probably because of pyruvate conversion and the latter because of the generation of an extra ATP. Of note, both strains metabolized citric acid in AE condition, although AL5 did so more than AL3. The draft genome of both strains showed the sequence encoding for CitP, a transporter belonging to the 2-hydroxycarboxylate transporter family which is involved in uptake system of citrate $[25,26]$. Interestingly, our results showed citrate depletion in the first growth period, even though the $\mathrm{pH}$ did not decrease rapidly. Moreover, we found sequences encoding for all subunits (gamma, beta, and alpha) of CL, the enzyme involved in citrate metabolism. In fact, this enzyme catalyzes the cleavage of citrate into oxaloacetate and acetate $[25,27,28]$. While the sequence encoding for the AOD enzyme, responsible of oxaloacetate conversion into pyruvate, was not found, BLAST analysis revealed the presence of the reductive TCA cycle genes encoding for MDH, FH, and SDH enzymes. Lactobacilli usually lack a complete TCA cycle, even though some strains are able to metabolize citrate via the reductive TCA cycle or via pyruvate lyase-oxaloacetate decarboxylase pathway [1,25]. Accordingly, Kang et al. [25] identified MDH, FH, and SDH as the enzymes involved in citrate conversion into succinate, via the reductive TCA cycle, in Lactobacillus panis PM1. To the best of our knowledge, this is the first time that sequences encoding for CitP enzyme has been annotated in the Lb. gasseri genome, while, sequences encoding for CL were annotated only in Lb. gasseri 32 (IMG/M database, https://img.jgi.doe.gov). As a matter of fact, $\mathrm{CL}$ and CitP occurrence is very limited among Lactobacilli genomes $[1,25,29]$. Although AE was the best growth condition for AL5, the strain showed a very low resistance to starvation stress. It has been demonstrated that the activation of the aerobic pathway, and/or of other enzymes involved in oxygen utilization, may result in a high production of $\mathrm{H}_{2} \mathrm{O}_{2}$ [30]. Hertzberger et al. [16] found that the endogenous production of $\mathrm{H}_{2} \mathrm{O}_{2}$ is the main cause of oxidative stress in the probiotic $\mathrm{Lb}$. johnsonii NCC 533 during aerobic growth. In the draft genome of AL5 we did not find sequences encoding for the catalase or pseudocatalase enzymes. Therefore, the possible toxic effect of $\mathrm{H}_{2} \mathrm{O}_{2}$ accumulation can explain the decreased survival of AL5 during long-term storage. Although the unique difference between AL3 and AL5 is in the presence of lao gene encoding for the flavoprotein L-amino acid oxidase, the two strains clearly showed a different energetic metabolism. All the genes here taken into account are that responsible of energetic metabolism, then we can suppose that difference is due to a different expression level of these genes. Regarding to $L b$. gasseri $20243^{\mathrm{T}}$, it showed the typical homo-fermentative behaviour. As expected, the anaerobiosis was the better growth condition, the glucose was the preferred carbon source and lactic acid was the main fermentation end-product. On the other hand, result of comparative in silico analysis revealed that $L b$. gasseri $20243^{\mathrm{T}}$ genome lacks genes encoding for NOX, LOX, L-amino acid oxidase, SOD and GshA enzymes. It was been noted that the mentioned enzymes are involved in oxygen tolerance and oxidative stress protection mechanisms in LAB [1]. Therefore, these evidences could explain the poor adaptation ability of $L b$. gasseri $20243^{\mathrm{T}}$ to AE condition. Moreover, Lb. gasseri $20243^{\mathrm{T}}$ genome lacks genes encoding for CitP, SDH and all subunits of CL enzyme, therefore its inability to use citrate is not surprising. On the contrary, despite the presence of genes encoding for components of a minimal respiratory chain of LAB (NDH, UbiE and CydABCD), Lb. gasseri $20243^{\mathrm{T}}$ was not able to grow in RS condition.

In conclusion, this work contributes to the understanding of the adaptation response of $L b$. gasseri strains to respiratory and aerobic metabolism. To date, this is the first study in which aerobic and respiratory growth has been evaluated in Lb. gasseri strains in batch cultivation. Lb. gasseri AL3 is confirmed to have a respiratory phenotype and AL5 an aerobic phenotype. We found that neither strain grew under anaerobiosis, the typical growth condition of $L b$. gasseri. The differences in growth kinetics and in metabolite profiles clearly suggest that several metabolic changes underlie the physiological characteristics observed. We demonstrated that a potential activation of respiratory metabolism can provide several advantages, such as improved biomass production and robustness during long-term storage. These features may be relevant in several technological and health-promoting applications, 
including starter and/or probiotic formulations. Further investigations will be performed on gene expression in AL3 and AL5, using a transcriptomic and proteomic approach to confirm the results of this study.

Author Contributions: Conceptualization, G.M. and D.M.; methodology, G.M. and D.M.; software, F.D.F.; validation, G.M. and D.M.; formal analysis, D.M. and A.R.; investigation, G.M., D.M., F.D.F., and A.R.; resources, G.M.; data curation, G.M., D.M. and F.D.F.; writing—original draft preparation, D.M.; writing—review and editing, G.M.; visualization, G.M.; supervision, G.M.; project administration, G.M. and D.M.; funding acquisition, G.M.

Conflicts of Interest: The authors declare no conflict of interest.

\section{References}

1. Zotta, T.; Parente, E.; Ricciardi, A. Aerobic metabolism in the genus Lactobacillus: Impact on stress response and potential application in the food industry. J. Appl. Microbiol. 2017, 122, 857-869. [CrossRef] [PubMed]

2. Sonomoto, K.; Atsushi, Y. Oxidative stress and oxygen metabolism in lactic acid bacteria. In Lactic Acid Bacteria and Bifidobacteria; Caister Academic Press: Poole, UK, 2011.

3. Pedersen, M.B.; Gaudu, P.; Lechardeur, D.; Petit, M.A.; Gruss, A. Aerobic respiration metabolism in lactic acid bacteria and uses in biotechnology. Annu. Rev. Food. Sci. Technol. 2012, 3, 37-58. [CrossRef] [PubMed]

4. Ianniello, R.G.; Zheng, J.; Zotta, T.; Ricciardi, A.; Ganzle, M.G. Biochemical analysis of respiratory metabolism in the heterofermentative Lactobacillus spicheri and Lactobacillus reuteri. J. Appl. Microbiol. 2015, 119, 763-775. [CrossRef] [PubMed]

5. Zotta, T.; Ricciardi, A.; Ianniello, R.G.; Parente, E.; Reale, A.; Rossi, F.; Iacumin, L.; Comi, G.; Coppola, R. Assessment of aerobic and respiratory growth in the Lactobacillus casei group. PLoS ONE 2014, 9, e99189. [CrossRef] [PubMed]

6. Ricciardi, A.; Ianniello, R.G.; Parente, E.; Zotta, T. Modified chemically defined medium for enhanced respiratory growth of Lactobacillus casei and Lactobacillus plantarum groups. J. Appl. Microbiol. 2015, 119, 776-785. [CrossRef] [PubMed]

7. Brooijmans, J.W.; de Vos, W.M.; Hugenholtz, J. Lactobacillus plantarum electron transport chain. Appl. Environ. Microbiol. 2009, 75, 3580-3585. [CrossRef] [PubMed]

8. Watanabe, M.; Van der Veen, S.; Nakajima, H.; Abee, T. Effect of respiration and manganese on oxidative stress resistance of Lactobacillus plantarum WCFS1. Microbiology 2012, 158, 293-300. [CrossRef] [PubMed]

9. Zotta, T.; Ricciardi, A.; Guidone, A.; Sacco, M.; Muscariello, L. Inactivation of ccpA and aeration affect growth, metabolite production and stress tolerance Lactobacillus plantarum WCFS1. Int. J. Food Microbiol. 2012, 155, 51-59. [CrossRef]

10. Zotta, T.; Ianniello, R.G.; Guidone, A.; Parente, E.; Ricciardi, A. Selection of mutants tolerant of oxidative stress from respiratory cultures of Lactobacillus plantarum C17. J. Appl. Microbiol. 2014, 116, 632-643. [CrossRef]

11. Reale, A.; Di Renzo, T.; Zotta, T.; Preziuso, M.; Boscaino, F.; Rocco, I.; Livia, V.S.; Patrizio, T.; Raffaele, C. Effect of respirative coltures of Lactobacillus casei on model sourdough fermentation. LWT Food. Sci. Technol. 2016, 73, 622-629. [CrossRef]

12. Reale, A.; Ianniello, R.G.; Ciocia, F.; di Renzo, T.; Boscaino, B.; Ricciardi, A.; Coppola, R.; Parente, E.; Zotta, T.; McSweeney, P.L.H. Effect of respirative and catalase-positive Lactobacillus casei adjuncts on the production and quality of Cheddar-type cheese. Int. Dairy. J. 2016, 63, 78-87. [CrossRef]

13. Neeser, J.; Granato, D.; Rouret, M.; Servin, A.; Teneberg, S.; Karlsson, K. Lactobacillus johnsonii La1 shares carbohydrate binding specificities with several enterophatogenic bacteria. Glycobiol. 2000, 10, 1193-1199. [CrossRef] [PubMed]

14. Sakai, F.; Hosoya, F.; Ono-Ohmachi, A.; Ukibe, K.; Ogawa, A.; Moriya, T.; Kadooka, Y.; Shiozaki, T.; Nakagawa, H.; Nakayama, Y.; et al. Lactobacillus gasseri SBT2055 Induces TGF-b expression in dendritic cells and activates TLR2 signal to produce IgA in the small intestine. PLoS ONE 2014, 9, 1-11. [CrossRef]

15. Holzapfel, W.H.; Wood, B.J.B. The genus Lactobacillus. In Biodiversity and Taxonomy; Wiley: New York, NY, USA, 2014.

16. Hertzberger, R.Y.; Pridmore, R.D.; Gysler, C.; Kleerebezem, M.; de Mattos, M. Oxygen relieves the $\mathrm{CO}_{2}$ and acetate dependency of Lactobacillus johnsonii NCC 533. PLoS ONE 2013, 8, e57235. [CrossRef] [PubMed] 
17. Hertzberger, R.Y.; Arents, J.; Dekker, H.; Pridmore, R.D.; Gysler, C.; Kleerebezem, M.; de Mattos, M.J. $\mathrm{H}_{2} \mathrm{O}_{2}$ production in species of the Lactobacillus acidophilus group: A central role for a novel NADH dependent flavin reductase. Appl. Environ. Microbiol. 2014, 80, 2229-2239. [CrossRef]

18. Maresca, D.; Zotta, T.; Mauriello, G. Adaptation to aerobic environment of Lactobacillus johnsonii/gasseri strains. Front. Microbiol. 2018, 9, 157. [CrossRef] [PubMed]

19. Maresca, D.; De Filippis, F.; Tytgat, H.L.P.; de Vos, W.M.; Mauriello, G. Draft genome sequences of the aerobic strains Lactobacillus gasseri AL3 and AL5. Genome Announc. 2017, 5, e00213-e00217. [CrossRef] [PubMed]

20. Duwat, P.; Sourice, S.; Cesselin, B.; Lamberet, G.; Vido, K.; Gaudu, P. Respiration capacity of the fermenting bacterium Lactococcus lactis and its positive effects on growth and survival. J. Bacteriol. 2001, 183, 4509-4516. [CrossRef] [PubMed]

21. Pedersen, M.B.; Garrigues, C.; Tuphile, K.; Brun, C.; Vido, K.; Bennedsen, M.; Møllgaard, H.; Gaudu, P.; Gruss, A. Impact of aeration and heme-activated respiration on Lactococcus lactis gene expression: Identification of a heme-responsive operon. J. Bacteriol. 2008, 190, 4903-4911. [CrossRef] [PubMed]

22. Guidone, A.; Ianniello, R.G.; Ricciardi, A.; Zotta, T.; Parente, E. Aerobic metabolism and oxidative stress tolerance in the Lactobacillus plantarum group. World J. Microbiol. Biotechnol. 2013, 29, 1713-1722. [CrossRef]

23. Rezaiki, L.; Cesseli, B.; Yamamoto, Y.; Vido, K.; West, E.; Gaudu, P. Respiration metabolism reduces oxidative and acid stress to improve long-term survival of Lactococcus lactis. Mol. Microbiol. 2004, 53, 1331-1342. [CrossRef] [PubMed]

24. Cesselin, B.; Derré-Bobillot, A.; Fernandez, A.; Lamberet, G.; Lachardeur, D.; Yamamoto, Y. Respiration, a strategy to avoid oxidative stress in Lactococcus lactis, is regulated by the heme status. Jpn. J. Lact. Acid Bact. 2010, 21, 10-15. [CrossRef]

25. Kang, T.S.; Korber, D.R.; Tanaka, T. Influence of oxygen on NADH recycling and oxidative stress resistance systems in Lactobacillus panis PM1. AMB Express. 2013, 3, 10-13. [CrossRef]

26. Mortera, P.; Pudlik, A.; Magni, C.; Alarcon, S.; Lolkema, J.S. Ca ${ }^{2+}$ Citrate uptake and metabolism in Lactobacillus casei ARCC 334. Appl. Environ. Microbiol. 2013, 79, 4603-4612. [CrossRef] [PubMed]

27. Subramanian, S.; Sivaraman, C. Bacterial citrate lyase. J. Biosci. 1984, 6, 379-401. [CrossRef]

28. Kanao, T.; Fukui, T.; Atomi, H.; Imanaka, T. Kinetic and biochemical analyses on the reaction mechanism of a bacterial ATP-citrate lyase. Eur. J. Biochem. 2002, 269, 3409-3416. [CrossRef] [PubMed]

29. Quintans, N.G.; Blancato, V.; Repizo, G.; Magni, C.; López1, P. Citrate metabolism and aroma compound production in lactic acid bacteria; Research Signpost: Irvine, CA, USA, 2008; ISBN 978-81-308-0250-3.

30. Teysset, C.M.; de La Torre, F.; Garel, J.R. Increased production of hydrogen peroxide by Lactobacillus delbrueckii subsp. bulgaricus upon aeration: Involvement of an NADH oxidase in oxidative stress. Appl. Environ. Microbiol. 2000, 66, 262-267. [CrossRef] [PubMed]

(C) 2019 by the authors. Licensee MDPI, Basel, Switzerland. This article is an open access article distributed under the terms and conditions of the Creative Commons Attribution (CC BY) license (http://creativecommons.org/licenses/by/4.0/). 